\title{
Evaluation and characterisation of Citrullus colocynthis (L.) Schrad seed oil: comparison with Helianthus annuus (sunflower) seed oil.
}

\begin{abstract}
The physicochemical properties, fatty acid, tocopherol, thermal properties, 1H NMR, FTIR and profiles of non-conventional oil extracted from Citrullus colocynthis (L.) Schrad seeds were evaluated and compared with conventional sunflower seed oil. In addition, the antioxidant properties of C. colocynthis seed oil were also evaluated. The oil content of the C. colocynthis seeds was $23.16 \%$. The main fatty acids in the oil were linoleic acid $(66.73 \%)$ followed by oleic acid (14.78\%), palmitic acid (9.74\%), and stearic acid $(7.37 \%)$. The tocopherol content was $121.85 \mathrm{mg} / 100 \mathrm{~g}$ with $\gamma$-tocopherol as the major one $(95.49 \%)$. The thermogravimetric analysis showed that the oil was thermally stable up to $286.57{ }^{\circ} \mathrm{C}$, and then began to decompose in four stages namely at $377.4{ }^{\circ} \mathrm{C}, 408.4{ }^{\circ} \mathrm{C}, 434.9^{\circ} \mathrm{C}$ and 559.2 ${ }^{\circ} \mathrm{C}$. The present study showed that this non-conventional C. colocynthis seed oil can be used for food and non-food applications to supplement or replace some of the conventional oils.
\end{abstract}

Keyword: Citrullus colocynthis; Helianthus annuus; Seed oil; Tocopherols; Fatty acids; Food \& cosmetic applications. 